\title{
Hubungan Nilai Ankle Brachial Index Dengan Kualitas Hidup Penderita Diabetes Melitus Tipe 2
}

\author{
Liana Safitri ${ }^{1}$, Fahrun Nur Rosyid ${ }^{2 *}$ \\ ${ }_{1}^{1}$ Universitas Muhammadiyah Surakarta, Surakarta 57162, Jawa Tengah, Indonesia \\ 2Departemen Keperawatan Medikal Bedah, Universitas Muhammadiyah Surakarta, Surakarta 57162, \\ Jawa Tengah, Indonesia. \\ * Korespodensi: fahrunnurrosyid@yahoo.com
}

\begin{abstract}
Abstrak: Salah satu komplikasi dari Diabetes Melitus Tipe 2 yang mempengaruhi sistem saraf perifer yaitu Peripheral Arthery Disease (PAD) . PAD dapat dideteksi dengan melakukan pemeriksaan nilai Ankle Brachial Index (ABI). Tes diagnostik PAD dengan akurasi ABI yang lebih besar kemungkinan mencerminkan perubahan dalam kualitas hidup seseorang terkait dengan kondisi yang dialami. Tujuan penelitian ini adalah untuk mengetahui adanya hubungan antara nilai ABI dengan kualitas hidup penderita DM. Jenis penelitian ini adalah analitik (survey) dengan menggunakan pendekatan cross sectional. Sampel yang digunakan pada penelitian ini yaitu 44 pasien DM tipe 2 di Persadia cabang Kota Surakarta. Teknik pengambilan sampel yang digunakan adalah purposive sampling. Instrumen yang digunakan untuk mencatat data menggunakan kuisioner, sphygmomanometer dan stetoskop. Berdasarkan hasil analisis menggunakan uji Chi-Square, diperoleh nilai $p=0,010(p<0,05)$ yang diartikan bahwa Ha diterima. Kesimpulan dari penelitian ini menunjukkan bahwa terdapat hubungan antara nilai ABI dengan kualitas hidup penderita DM di Persadia cabang Kota Surakarta.
\end{abstract}

Kata Kunci : Diabetes Melitus, Ankle Brachial Index, Kualitas Hidup

Abstract: One complication of Type 2 Diabetes Mellitus that affects the peripheral nervous system is Peripheral Artery Disease (PAD). PAD can be detected by checking the Ankle Brachial Index (ABI). PAD diagnostic tests with greater ABI accuracy are likely to reflect changes in a person's quality of life related to the conditions experienced. The purpose of this study was to determine the relationship between ABI values with the quality of life of people with DM. This type of research is analytic (survey) using a cross sectional approach. The sample used in this study were 44 type 2 DM patients in the Surakarta City branch of Persadia. The sampling technique used was purposive sampling. The instrument used to record data using a questionnaire, sphygmomanometer and stethoscope. Based on the analysis using the Chi-Square test, the value of $p=0.010(p<0.05)$ is obtained which means that Ha is accepted. The conclusion of this study shows that there is a relationship between the value of ABI with the quality of life of patients with DM in the Surakarta branch of Persadia.

Keywords: Diabetes Mellitus, Ankle Brachial Index, Quality of Life 


\section{PENDAHULUAN}

Prevelensi Diabetes Melitus setiap tahunnya semakin meningkat, berdasarkan data dari World Health Organizaton (WHO) penderita DM di dunia tahun 2000 berjumlah 171 juta dan diprediksikan meningkat menjadi tiga kali lipatnya, yaitu sekitar 366 juta penderita di tahun 2030. Di Indonesia sendiri jumlah penderita DM mencapai 8.4 juta dan akan meningkat menjadi 21.2 juta pada tahun 2030 (WHO, 2012).

Peningkatan prevalensi data penderita DM di atas salah satunya yaitu Provinsi Jawa Tengah yang mencapai 152.075 kasus (Dinas Kesehatan Provinsi Jawa Tengah, 2011). Angka kejadian DM di Persadia cabang Surakarta beranggotakan 200 orang dan yang menderita DM tipe 2 sebanyak 80 orang (Buku Register Persadia Surakarta).

Penderita DM tipe 2 memiliki resiko komplikasi yang tidak jauh berbeda dengan DM tipe 1 (Smeltzer \& Bare, 2008). Komplikasi DM secara umum di bagi menjadi 2 (dua), yaitu komplikasi akut (hipoglikemi, hiperglikemia ketoasidosis dan hiperglikemia hyperosmolar nonketotik) serta komplikasi kronis (Penyakit jantung koroner, penyakit serebrovaskular, hipertensi, infeksi, penyakit vaskular perifer, penyakit arteri perifer, neuropati, retinopati, dan ulkus kaki diabetik) (Black \& Hawks, 2009).

Salah satu komplikasi dari Diabetes Melitus Tipe 2 yang mempengaruhi sistem saraf perifer yaitu Peripheral Arthery Disease (PAD) merupakan suatu kondisi dimana terdapat lesi di pembuluh darah sehingga menyebabkan aliran darah dalam arteri yang mensuplai darah ke ekstremitas menjadi terbatas dan penyakit ini juga sangat ditakuti karena mempengaruhi kualitas hidup dan fungsi sosial penderitanya (Williams \& Wilkins, 2011).

Keterlibatan vaskular sedikit unik dimana tersering pada pembuluh darah dibawah lutut dan hampir selalu disertai dengan neuropati. Oleh sebab itu, sering tanpa gejala atau hanya merasakan keluhan yang tidak jelas tidak seperti gejala klasik PAD seperti klaudikasio intermiten. Sehingga sebagai konsekuensi dari adanya neuropati, sering penderita PAD dan diabetes datang terlambat dan sudah dengan gejala rest pain, ulkus sampai gangren (ADA, 2015).

Pemeriksaan lanjutan yang diperlukan pada kecurigaan adanya PAD adalah pengukuran Ankle Brachial Index (ABI) yang merupakan rasio tekanan darah pada ankle dan brachial. Nilai ABI dianggap normal apabila $\geq 1.0$ sedangkan nilai $\mathrm{ABI} \leq 0.9$ dapat membantu menegakkan diagnosis PAD (Williams \& Wilkins, 2011).

PAD dikaitkan dengan kemampuan fisik berkurang dan penurunan fungsional. Kondisi ini dapat menyebabkan berkurangnya kualitas hidup seseorang (Health Related Quality Of Life) dibandingkan dengan penyakit kardiovaskular karena sakit, gangguan tidur dan mengurangi mobilitas fisik. Tes diagnostik PAD dengan akurasi ABI yang lebih besar kemungkinan mencerminkan perubahan dalam kualitas hidup seseorang (HRQOL) terkait dengan kondisi yang dialami (Sonter \& Chuter, 2016).

Berdasarkan hasil observasi di Persadia Cabang Surakarta pada 6 angggota Persadia, didapatkan 3 orang memiiki nilai ABI 0.92; 2 orang memiliki nilai ABI 0, 86 ; dan 1 orang memiliki nilai ABI 0.85. Masing-masing anggota mempunyai keluhan yang sama yaitu dapat melakukan aktivitas sehari-hari secara mandiri namun sering muncul tanda-tanda klaudikasio intermiten apabila melakukan aktivitas yang berlebih seperti nyeri pada kaki, kesemutan, cepat lelah serta pucat pada ekstremitas bawah. Permasalahan inilah yang mendorong peneliti untuk melakukan penelitian tentang Hubungan Ankle Brachial Index (ABI) dengan Kualitas Hidup Penderita Diabetes Mellitus Tipe 2 di Persadia Cabang Kota Surakarta

\section{METODE}

Rancangan penelitian ini adalah analitik (survey), yang menggunakan pendekatan penelitian cross sectional di mana data yang menyangkut variabel bebas dan variabel terikat akan dikumpulkan dalam waktu yang bersamaan. Populasi dalam penelitian ini adalah semua penderita Diabetes Mellitus Tipe 2 sebanyak 80 orang. Sampel penelitian ini adalah penderita Diabetes Melitus tipe 2 di Persadia Cabang 
Kota Surakarta tahun 2017 dengan jumlah 44 penderita. Penelitian ini menggunakan nonprobability sampling dengan jenis pengambilan sampel purposive sampling sesuai dengan kriteria. Penelitian ini menggunakan alat ukur kuesioner untuk mengukur kualitas hidup dan sphygmomanometer untuk mengukur nilai ABI. Analisa sata pada penelitian ini menggunakan teknik Chi Square.

HASIL

Analisis Bivariat

Tabel 1. Karakteristik Responden Menurut Usia

\begin{tabular}{|c|c|c|c|c|c|c|}
\hline & Frekuensi & Persen & $\begin{array}{l}\text { Valid } \\
\text { Persen }\end{array}$ & $\begin{array}{c}\text { Cumulativ } \\
\text { Persen }\end{array}$ & & \\
\hline $\begin{array}{l}50-59 \\
\text { tahun }\end{array}$ & 17 & 38.6 & 38.6 & 38.6 & 1.61 & 0.493 \\
\hline $\begin{array}{l}60-74 \\
\text { tahun }\end{array}$ & 27 & 61.4 & 61.4 & 100.0 & & \\
\hline Total & 44 & 100.0 & 100.0 & & & \\
\hline
\end{tabular}

Tabel 2. Karakteristik responden menurut jenis kelamin

\begin{tabular}{|c|c|c|c|c|c|c|}
\hline & Frekuensi & Persen & $\begin{array}{l}\text { Valid } \\
\text { Persen }\end{array}$ & $\begin{array}{l}\text { Kumulatif } \\
\text { Persen }\end{array}$ & & \\
\hline Laki-laki & 14 & 31.8 & 31.8 & 31.8 & 1.68 & 0.471 \\
\hline Perempuan & 30 & 68.2 & 68.2 & 100.0 & & \\
\hline Total & 44 & 100.0 & 100.0 & & & \\
\hline
\end{tabular}

Tabel 3. Karakteristik responden menurut tingkat pendidikan

\begin{tabular}{lllllll}
\hline & Frekuensi & Persen & $\begin{array}{l}\text { Valid } \\
\text { Persen }\end{array}$ & $\begin{array}{l}\text { Kumulatif } \\
\text { Persen }\end{array}$ & & \\
\hline Rendah & 18 & 40.9 & 40.9 & 40.9 & 0.75 & 0.719 \\
\hline Menengah & 19 & 43.2 & 43.2 & 84.1 & & \\
\hline Tinggi & 7 & 15.9 & 15.9 & 100.0 & \\
\hline Total & 44 & 100.0 & 100.0 & & & \\
\hline
\end{tabular}

Tabel 4. Karakteristik lama menderita DM

\begin{tabular}{lllllll}
\hline & Frekuensi & Persen & $\begin{array}{l}\text { Valid } \\
\text { Persen }\end{array}$ & $\begin{array}{l}\text { Kumulatif } \\
\text { Persen }\end{array}$ & & \\
\hline Sedang & 32 & 72.7 & 72.7 & 72.7 & 1.27 & 4.51 \\
\hline Panjang & 12 & 27.3 & 27.3 & 100.0 & & \\
\hline Total & 44 & 100.0 & 100.0 & & & \\
\hline
\end{tabular}

Tabel 5. Distribusi nilai ABI

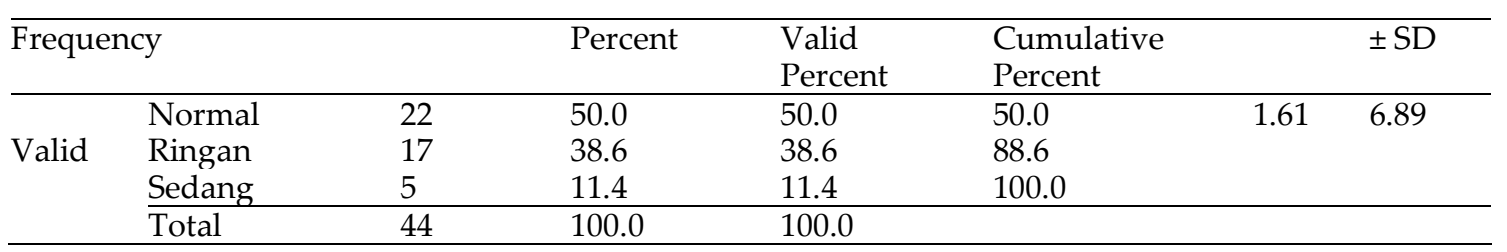


Tabel 6. Distribusi kualitas hidup

\begin{tabular}{|c|c|c|c|c|c|c|}
\hline & Frequency & Percent & $\begin{array}{l}\text { Valid } \\
\text { Percent }\end{array}$ & $\begin{array}{l}\text { Cumulative } \\
\text { Percent }\end{array}$ & & \\
\hline Kurang baik & 17 & 38.6 & 38.6 & 38.6 & 0.61 & 0.493 \\
\hline Baik & 27 & 61.4 & 61.4 & 100.0 & & \\
\hline Total & 44 & 100.0 & 100.0 & & & \\
\hline
\end{tabular}

Analisis Bivariat

Tabel 4.7 Frekuensi ABI dengan kualitas hidup

\begin{tabular}{|c|c|c|c|c|c|c|c|c|}
\hline \multirow{3}{*}{ ABI } & \multicolumn{2}{|c|}{$\frac{\text { Kualias }}{\underline{\text { hidup }}}$} & & \multicolumn{3}{|c|}{ Total } & \multirow[t]{2}{*}{$X^{2}$} & \multirow[t]{2}{*}{$p$} \\
\hline & \multicolumn{2}{|c|}{ Kurang baik } & \multicolumn{2}{|l|}{ Baik } & & & & \\
\hline & Frek & $\%$ & Frek & $\%$ & Frek & $\%$ & & \\
\hline Normal & 6 & 27.3 & 16 & 72.7 & 22 & 50 & 9.220 & 0.010 \\
\hline Ringan & 6 & 35.3 & 11 & 64.7 & 17 & 38.6 & & \\
\hline Sedang & 5 & 29.4 & 0 & 0 & 5 & 11.4 & & \\
\hline
\end{tabular}

Dari tabel diatas dapat diketahui bahwa distribusi responden yang memiliki nilai ABI normal dengan kualitas hidup kurang baik sebanyak 6 responden $(35.3 \%)$ dan responden yang memiliki nilai ABI normal dengan kualitas hidup baik sebanyak 16 responden (59.3\%).

Sedangkan responden yang memiliki nilai ABI abnormal (ringan) dengan kualitas hidup kurang baik sebanyak 6 responden (35.5\%) dan responden memiliki nilai ABI abnormal (ringan) dengan kualitas hidup baik sebanyak $40.7 \%$ ) serta responden yang memiliki nilai ABI abnormal (sedang) dengan kualitas hidup kurang baik sebanyak 5 responden (29.4\%). Hasil yang didapatkan dari uji chi square adalah nilai $p$-value $=0,010$ yang berarti nilai $p$-value $<0,05$ sehingga Ho ditolak dan Ha diterima. Sehingga dapat disimpulkan bahwa terdapat hubungan signifikan antara nilai ABI dengan kualitas hidup penderita DM tipe 2 di Persadian cabang Kota Surakarta

\section{PEMBAHASAN}

\section{Karakteristik responden}

Distribusi umur responden menunjukan sebagian besar responden merupakan kelompok lansia. Golberg dan Coon dalam Rochmah (2006) menyatakan bahwa umur sangat erat kaitannya dengan kenaikan kadar glukosa darah, sehingga semakin meningkat usia maka prevalensi diabetes dan gangguan toleransi glukosa semakin tinggi.

Karakteristik responden menurut jenis kelamin yang tertinggi adalah perempuan yaitu sebanyak 27 responden (61,36\%). Distribusi jenis kelamin responden menunjukan sebagian besar responden merupakan perempuan. Hal ini sejalan dengan penelitian Chaveepohjkamjorn et al (2008) mengenai kualitas hidup dan kepatuhan pasien DM tipe 2, sebagian mayoritas (78,7\%) adalah perempuan.

Tingkat pendidikan sebagian besar responden berada pada kategori rendah, yaitu SD-SMP sebanyak 18 responden (40.9\%). Hal in sejalan dengan penelitian Mier et al (2008) dalam study cross sectional pada pasien DM tipe 2, menemukan sebagian besar responden memiliki pendidikan yang rendah (70\%). Begitu juga pada penelitian Wen et al (2004), dimana responden DM tipe 2 yang memiliki pendidikan rendah lebih banyak dibanding pendidikan tinggi.

Peneliti berasumsi bahwa tingkat pendidikan mempengaruhi perilaku seseorang dalam mencari perawatan dan pengobatan penyakit yang dideritanya, serta memilih dan memutuskan tindakan atau terapi yang akan dijalani untuk mengatasi masalah kesehatannya.

Lama menderita DM tertinggi dengan kategori sedang (5-10 tahun) yaitu sebanyak 32 responden (72,7\%). Hal ini sesuai dengan penelitian oleh Arnadi et al. bahwa kebanyakan kasus DM akan 
mengalami komplikasi PAP setelah perjalanan penyakitnya $>5$ tahun $(P=0,044)$. Jika kadar glukosa darah tinggi, maka akan timbul komplikasi yang berhubungan dengan saraf dan aliran darah ke kaki. Kelainan vaskuler sebagai manifestasi patologis DM dari pada sebagai penyulit karena erat hubungannya dengan kadar glukosa darah yang abnormal, sedangkan untuk mudahnya terjadinya infeksi seperti tuberkolosis atau gangrene diabetik lebih sebagai komplikasi (Waspadji, 2009).

\section{Distribusi frekuensi Nilai ABI}

Nilai ABI normal didapatkan paling banyak yaitu sebanyak 22 responden (50\%), sedangkan responden dengan nilai $\mathrm{ABI}$ ringan sebanyak 17 responden (11.4)\% dan responden yang mempunyai nilai $\mathrm{ABI}$ sedang sebanyak 5 responden $(11.4 \%)$. Hal ini sejalan dengan penelitian Kristiani, Sumangku, \& Limpeleh mengenai Hubungn nilai ABI dengan kejadian ulkus didapatkan hasil nilai ABI normal didapatkan paling banyak yaitu pada 22 pasien $(57,9 \%)$, diikuti oleh obstruksi vaskular sedang (8 pasien - 21,1\%), iskemi ringan (7 pasien - 18,4\%), dan hanya 1 pasien $(2,6 \%)$ dengan obstruksi vaskular berat. Pada penelitian ini nilai ABI normal banyak didapatkan pada ulkus derajat 1 dan 3 (77,8\% dan 75\%), sedangkan obstruksi vaskular berat hanya didapatkan pada ulkus derajat (Kemenkes RI, 2013).

\section{Distribusi Frekuensi Kualitas Hidup}

Hasil dari penelitian menunjukkan jumlah responden yang mempunyai kualitas hidup baik sebanyak 27 orang $(38,6 \%)$ sedangkan 17 orang mempunyai kualitas hidup kurang baik $(61,4 \%)$. Kualitas hidup dapat diartikan sebagai derajat dimana seseorang menikmati kemungkinan dalam hidupnya, kenikmatan tersebut memiliki dua komponen yaitu pengalaman, kepuasan dan kepemilikan atau pencapaian beberapa karakteristik dan kemungkinan-kemungkinan tersebut merupakan hasil dari kesempatan dan keterbatasan setiap orang dalam hidupnya dan merefleksikan interaksi faktor personal lingkungan (Weissman \& Chang, 2004).

\section{Hubungan Nilai ABI dengan Kualitas Hidup}

Hasil analisis hubungan antara nilai Ankle Brachial Indeks (ABI) dengan Kualitas menunjukkan nilai ABI dengan kualitas hidup pasien DM kurang baik. Hasil uji statistik lebih lanjut disimpulkan ada hubungan yang bermakna antara Nilai ABI dengan kualitas hidup responden ( $p$ value $=0.010$ ).

Hal ini sejalan dengan penelitian Sonter \& Chuter (2016), bahwa Nilai ABI dengan Kualitas Hidup mempunyai hubungan bermakna. Pada ekstremitas bawah, penyakit arteri perifer (PAD) memiliki gejala asimtomatik atau dengan gejala nyeri iskemik, luka yang proses penyembuhanya lama dan kehilangan jaringan. Bahkan tanpa adanya gejala, PAD dikaitkan dengan kemampuan fisik berkurang dan penurunan fungsional. Kondisi ini dapat menyebabkan berkurangnya kualitas hidup seseorang (Health Related Quality Of Life) dibandingkan dengan penyakit kardiovaskular karena sakit, gangguan tidur dan mengurangi mobilitas. Tes diagnostik PAD dengan akurasi ABI yang lebih besar kemungkinan mencerminkan perubahan dalam kualitas hidup seseorang (HRQOL) terkait dengan kondisi yang dialami (Sonter \& Chuter, 2016).

Menurut asumsi peneliti, terganggunya sirkulasi daerah perifer akibat PAD menyebabkan klaudikasio intermiten dengan gejala khas nyeri pada tungkai bawah sehingga mobilitas terganggu. Jika hal ini dibiarkan terus menerus terjadi maka kualitas hidup akan mengalami penurunan terutama pada domain ketahanan serta kekuatan fisik.

\section{KESIMPULAN}

Kesimpulan penelitian ini adalah nilai ABI terbanyak penderita DM di Persadia Cabang Kota Surakarta yaitu dengan rentan nilai ABI normal, kemudian disusul dengan nilai ABI ringan, dan yang paling terendah adalah nilai ABI sedang. Kualitas hidup penderita DM di Persadia Cabang Kota Surakarta terbanyak adalah baik. durasi diabetes melitus yang panjang disertai dengan kepatuhan dan pengontrolan gula darah yang tepat walaupun telah terkena komplikasi tentunya akan membuat 
pasien memiliki kualitas hidup yang baik dan terpelihara. Terdapat hubungan yagng signifikan antara ABI dengan Kualitas Hidup Penderita DM di Persadia Cabang Kota Surakarta.

Saran penelitian ini bagi tenaga kesehatan diharapkan pada petugas Persadia untuk lebih aktif memberikan penyuluhan kesehatan pada pasien diabetes melitus dalam pencegahan (deteksi dini komplikasi) serta penanganan komplikasi DM. Bagi pasien diabetes mellitus diharapkan lebih optimis lagi dalam menjalani hidup sehat agar kualitas hidup yang baik tetap terjaga terutama pada pasien yang telah terkena komplikasi kronik (PAP) dengan cara menjaga diit yang teratur, menghindari stress dan mendapatkan dukungan dari keluarga. Bagi peneliti perlu melengkapi lagi pertanyaan dari domain yang belum tercantum, meringkas kembali item pertanyaan yang terlalu banyak serta penambahan waktu saat mengerjakan kuesioner.

\section{DAFTAR PUSTAKA}

Aboyans, V., Lacroix, P., Tran, M.H., Salamagne, C., Galinat, S., Archambeaud, F., et al. (2012). The prognosis of diabetic patients with high anklebrachial index depends on the coexistence of occlusive peripheral artery disease. J Vasc Surg 53 ; 984-91.

American Diabetes Association (2015). Diagnosis and Classification of Diabetes Mellitus,Diabetes Care,38:8-16.

Black, J., \& Hawk, J. H. (2009). Medical Surgical Nursing. Clinical Management for Positif Outcomes (6 $\left.6^{\text {th }}\right)$. Saunders: Elsevier.

Bryant, R.A., \& Nix, D.P. (2006). Acute and Chronic Wounds: Current Management Concepts $3^{\text {rd }}$ Edition, Mosby, St Louis.

Buku profil kesehatan Provinsi jawa tengah Tahun 2011.

Chaveepojnkamjorn, W., Pichainarong, N., Schelp, F.P., \& Mahaweerawat M.U. (2008). Quality of life and compliance among type 2 diabetic patient. Southest Asian Journal Trop Med, Public health,39 (2), 328-334.

Hidayat, A.A. (2014). Metode Penelitian Kebidanan dan Teknik Analisa Data. Jakarta : Salemba Medika.

Isa B. A. and O. Baiyewu. (2006). Quality of life with diabetes mellitus in a Nigerian Teaching Hospital. Hongkong Journal Psychiatry . 27-33.

Kemenkes. Riset Kesehatan Dasar: Riskesdas 2013. Jakarta: Badan Penelitian dan Pengembangan Kesehatan Kementrian Kesehatan RI, 2013.

Kirsner, R.S. (2010). The Standart of Care for Evaluation and Treatment of Diabetic Foot Ulcers.

Nagpal J., Kumar A., Kakar S., Bhartia A. (2010). The Development of ‘Quality of Life Instrument for Indian Diabetes Patients (QOLID) : A Validation and Reliability Study in Middle and Higher Income Groups. JAPI May vol. 58.

Nahler M.R., McDermott M.M., Treat-Jacobsonc D., Chetterd I.,and Regensteiner J.G. (20003). Functional outcomes and quality of life in peripheral arterial disease: Current status. 8: 115- 126.

PERKENI., (2011). Konsensus Pengelolaan dan Pencegahan Diabetes Mellitus Tipe 2 di Indonesia. Jakarta

Rochmah, W., 2006, Diabetes Melitus Pada Usia Lanjut, Buku Ajar Ilmu Penyakit Dalam, Edisi Ketiga, Editor Suyono, S., 1857, Balai Penerbit FKUI, Jakarta.

Roza, R.L., Afriant, R., \& Edward, Z.(2015). Faktor Resiko Terjadinya Ulkus Diabetium pada Pasien Diabetes Melitus. Skripsi Ilmiah. Padang : Fakultas Kedokteran Universitas Andalas Padang. Sonter and Chuter. Health and Quality of Life Outcomes (2016) 14:50 DOI 10.1186/s12955-0160451-5.

Waspadji S. Kaki diabetes. Dalam: Sudoyo A.W., Setiyohadi B., Alwi I., Simadibrata M., Setiati S. (2009). editors. Buku Ajar Ilmu Penyakit Dalam, Jilid III, edisi kelima. Jakarta: Interna publishing.

Wen, L.K., Parchman ML. \& Shepard M.D.., (2004). Family support and diet barriers among older Hispanic adults with type 2 diabetes. Clinical Research and Methods. 36 (6), 423-430.

Williams, L \& Wilkins (2011). Nursing : Memahami Berbagai Macam Penyakit. Alih Bahasa Paramita. Jakarta : PT. Index. 